\title{
Quantitative microscopical and histochemical study of the skin of mice under the effect of exposure to ultra violet rays type-B
}

\author{
Somaya H. Mohamed*, Fouad M. Badr*, Howayda Abed El-Aal ${ }^{\dagger}$, Rushdy W. \\ Mohamed $^{\ddagger}$, and Bassem S. Ahmed ${ }^{\bullet}$
}

From Departments of Histology*, Pathology ${ }^{\dagger}$ and Dermatology $y^{\ddagger}$ Suez Canal Faculty of Medicine and Histology department Al-Azhar Faculty of Medicine - Assuit ${ }^{\bullet}$

\begin{abstract}
The modern industrial era, has benefits and also disadvantages. The main disadvantages are environmental pollution and ozone layer depletion. Ozone layer depletion leads to failure of absorption and prevention of harmful rays from penetration of earth atmosphere.

The current work studied the effect of ultra violet-B rays on the skin of mice. Twenty-four mice were subjected to ultra violet-B rays in dose of $1.4 \mathrm{~J} / \mathrm{cm}^{2}$ for 15 minutes every other day for 10 weeks.

Paraffin sections slides were prepared and stained with suitable histological stains to study the morphology, collagen and elastic fibers, mast cells and glycosaminoglycans materials in the skin.

The study included quantitative morphometric analysis by image analyzer on some obtained data. The study revealed a statistically significant increase in the epidermal thickness $(\mathrm{p}<0.001)$, associated with necrotic cells, compact ortho-keratosis in the stratum corneum. A degenerated collagen fibers was observed in exposed dermal skin with statistically significant decrease in optical density of collagen fibers $(\mathrm{p}<0.001)$. There was a loss of elastic fibers fibrillary pattern. Also there was an increase in melanin pigments concentrations, mast cells, deposition of PAS positive materials in the basement membrane at dermo-epidermal junction, around blood vessels, sebaceous and sweat glands and hair follicles.

The study concluded that there was a defined pathological change in the skin exposed to ultraviolet rays and adequate protective prophylactic application must be used to minimize the effect of ultraviolet radiations exposures.
\end{abstract}

\section{Introduction}

Solar rays contain a spectrum of light wavelengths with range of $200-400 \mathrm{~nm}$. These spectrum is subdivided into 3 categories; Ultraviolet A (with range of $320-400 \mathrm{~nm}$ ), Ultraviolet B (290-320nm) and Ultraviolet C (200-290nm). Ultraviolet $C$ is the most potent and dangerous rays and is absorbed by ozone layer and doesn't reach the earth. Ultraviolet $\mathrm{B}$ is responsible for most of photodamage of human skin. Ultraviolet $\mathrm{A}$ is weak rays (Kaminar, 1995). Clinically ultraviolet rays exposure causes photodamage of the skin. The photodamage includes; wrinkles (fine and coarse), roughness, laxity, mottled pigmentation, actinic (lentigines and keratosis), scaling, xerosis and telangiectasia (Leyden, 2001). Many factors can accelerate the effect of exposure to UV rays on the skin; time of the day, season of the year, duration to exposure, skin thickness and skin color (Harber et al., 1989). Photodamage and photoaging are associated with an increased incidence of benign, pre-malignant and malignant skin lesions (Griffith 1992). According to US environmental protection agency, the continuous ozone layer depletion 
(1\% decrease in stratospheric ozone increases amount of ultraviolet $\mathrm{B}$ penetration to earth by $2 \%$ ) will cause an increase in skin cancer mortality in the next 50 years (Welsh et al., 1999).

\section{Materials and Methods}

Twenty-four adult male mice were subjected to the study. A pre-defined shaved area of $2 \mathrm{~cm} \times 2 \mathrm{~cm}$ was selected in the back of each for ultraviolet exposure. Ultraviolet B rays was obtained by using Fs-40 sun-lamp produced $1.4 \mathrm{~J} / \mathrm{cm}^{2}$ of wavelength 290 $320 \mathrm{~nm}$. The lamp was placed $25 \mathrm{~cm}$ from the back of mice for 15 minutes per session, on alternate days for 10 weeks (Chen et al 1992). Mice were sacrificed after $24 \mathrm{hrs}$ of last exposure to ultraviolet rays. Two skin biopsies were taken; one from the exposed area and represent experimental sample and the other from non-exposed area and represented a control sample for each mice. The skin biopsies were fixed in neutral buffered formol and processed for preparation of $4 \mathrm{um}$ thick paraffin section slides. The paraffin sections were stained by Hematoxylin and Eosin stain for morphological change, Masson trichrome stain for demonstration of skin collagen. Demonstration of elastic fibers was done by Orcein stain, Masson Fontana technique for evaluation of melanin pigment, while Thionin technique was used for demonstration of mast cells. Periodic Acid Schiff (PAS) technique was applied for detection of glycosaminoglycans of skin (Drury and Wallington, 1996). Quantitative morphometric studies were done by the aid of Leica Image analyzer system. The quantitative studies were done on twenty field for each mice and included thickness of epidermis, melanin pigments distribution as an area percent, Collagen fibers condensation as an optical density. The obtained data were statistically analyzed using student t-Test for comparison between exposed and non-exposed areas.

\section{Results \\ Morphometric Results:}

\section{Non-exposed Skin: (Control)}

The normal non-exposed skin of mice showed very thin epidermis, with ill-defined strata, stratum basale cells had clear oval nuclei (Plate1-A and Plate1-C).

By Masson trichrome stain, fine collagenous fibers were demonstrated in the papillary dermis, and dense irregular collagenous fibers in the reticular dermis (Plate1-E).

By Orcein technique the dermis showed fine dark brown thin elastic fibers arranged sparsely in fibrillary pattern (Plate 2-A).

Melanin pigments were demonstrated in non-exposed skin by Masson's Fontana technique, mainly in the hair follicles and scattered areas in the epidermis (Plate 2-C). Thionin technique demonstrated mast cell in the non-exposed skin as few ovoid purplish cells scattered in the dermis (Plate 2-E).

Plate2-G showed the normal distribution of PAS positive materials (glycosaminoglycans) in the basement membrane at dermo-epidermal junction, around blood vessels, sebaceous and sweat glands and hair follicles.

\section{Exposed Skin:}

In the area exposed to ultraviolet $\mathrm{B}$, skin showed an increase in the epidermal thickness (Plate1-D) associated with necrotic cells in the form of vacuolated cytoplasm and pyknotic nuclei. There was an increase of mitotic figures and compact ortho-keratosis in the stratum corneum (Plate1-D).

The dermis showed degenerated dermal collagen in the reticular dermis and appeared as delicate fragmented strands of collagen fibers (Plate1-F).

There was an increase in the thickness of elastic fibers and loss of their fibrillary pattern in comparison to non-exposed skin of same mice (Plate 2-B).

In comparison to non-exposed skin, 
there was a marked increase in the melanin pigments appeared as irregular heterogeneous black clusters in the epidermis and hair follicles (Plate 2-D).

Abundant mast cells were observed in the dermis of exposed mice skin especially around blood vessels (Plate 2-F)

There was an increase in deposition of PAS positive materials in the basement membrane at dermo-epidermal junction, around blood vessels, sebaceous and sweat glands and hair follicles in comparison to non-exposed skin of same mice (Plate 2-H).

Quantitative Results:- (Table-1)

The mean thickness of epidermis of non-exposed area was $16.485 \mathrm{um}, \mathrm{SD}$ was 4.977 and SEM was 1.437. After exposure the mean was $54.718 \mathrm{um}$, SD was 4.977 and SEM was 6.395. There was statistically significant increase in the epidermal thickness in exposed skin in comparison to their nonexposed area $(\mathrm{p}<0.001)$ (Fig. 1).

The collagen fibers concentration was evaluated as optical density, the mean of nonexposed area was 1.244, SD was 0.05 and SEM was 0.014. After exposure the mean was 1.038, SD was 0.092 and SEM was 0.027 . There was statistically significant decrease in the optical density of collagen fibers in exposed skin in comparison to their non-exposed area $(\mathrm{p}<0.001)$ (Fig. 2).

The melanin pigments distribution was analyzed as area percentage (\%), the mean of non-exposed area was 2.423 , SD was 0.286 and SEM was 0.083 . After exposure the mean was 3.202, SD was 0.234 and SEM was 0.068 . There was statistically significant increase in the melanin pigments area percentage in exposed skin in comparison to their non-exposed area $(\mathrm{p}<0.001)$ (Fig. 3).

Table -1 Effect of exposure to ultra violet-B rays on the epidermal thickness, dermal collagen and melanin distribution of mice skin

\begin{tabular}{|c|c|c|c|c|c|c|}
\hline & Mean & SD & SEM & t-Test & $\mathrm{p}$-value & $\begin{array}{l}\text { Significanc } \\
\mathrm{e}\end{array}$ \\
\hline \multicolumn{7}{|c|}{ Epidermal thickness (?m) } \\
\hline Non-Exposed & 16.485 & 4.977 & 1.437 & \begin{tabular}{|l} 
Exposed \\
vs Non- \\
Exposed
\end{tabular} & & \\
\hline Exposed & 54.718 & 22.154 & 6.395 & $7.20 \mathrm{E}-06$ & $\mathrm{p}<0.001$ & Increase \\
\hline \multicolumn{7}{|c|}{ Collagen fibers (O.D.) } \\
\hline Non-Exposed & 1.244 & 0.05 & 0.014 & \begin{tabular}{|l|} 
Exposed \\
vs Non- \\
Exposed
\end{tabular} & & \\
\hline Exposed & 1.038 & 0.092 & 0.027 & $7.99 \mathrm{E}-07$ & $\mathrm{p}<0.001$ & Decrease \\
\hline \multicolumn{7}{|c|}{ Melanin distribution area (\%) } \\
\hline Non-Exposed & 2.423 & 0.286 & 0.083 & \begin{tabular}{|l|} 
Exposed \\
vs Non- \\
Exposed
\end{tabular} & & \\
\hline Exposed & 3.202 & 0.234 & 0.068 & $2.62 \mathrm{E}-07$ & $\mathrm{p}<0.001$ & Increase \\
\hline
\end{tabular}

N.B. 1-Number of readings was 20 fields for non-exposed and exposed area per mice (total 480 readings)

$2-\mathrm{SD}=$ Standard deviation $\mathrm{SEM}=$ Standard error of mean $\quad \mathrm{t}$-Test $=$ Student's $\mathrm{T}$ test p-value $=$ Probability

3- O.D.=Optical Density 4- $\mathrm{p}<0.05$ was considered as statistically significance 
Figure-1 Effect of exposure to ultra violet$B$ rays on the epidermal thickness of mice skin

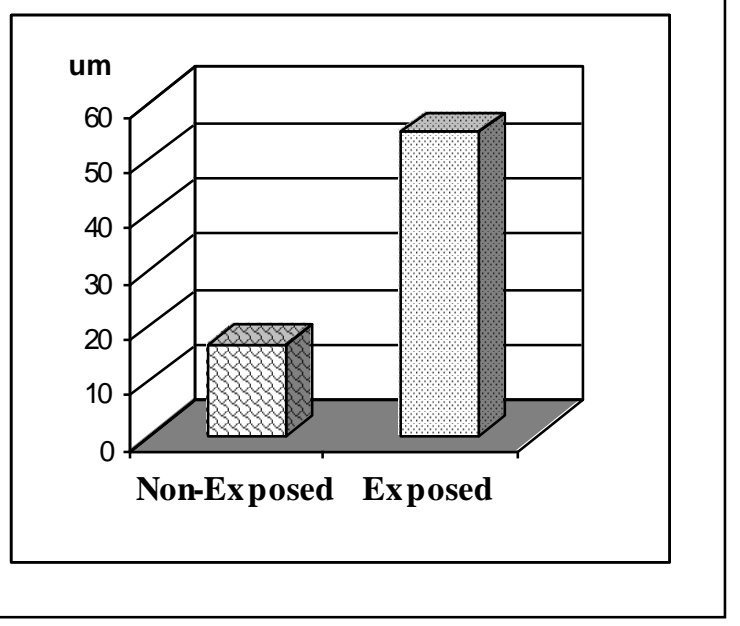

Figure-2 Effect of exposure to ultra violet-B rays on the dermal collagen of mice skin

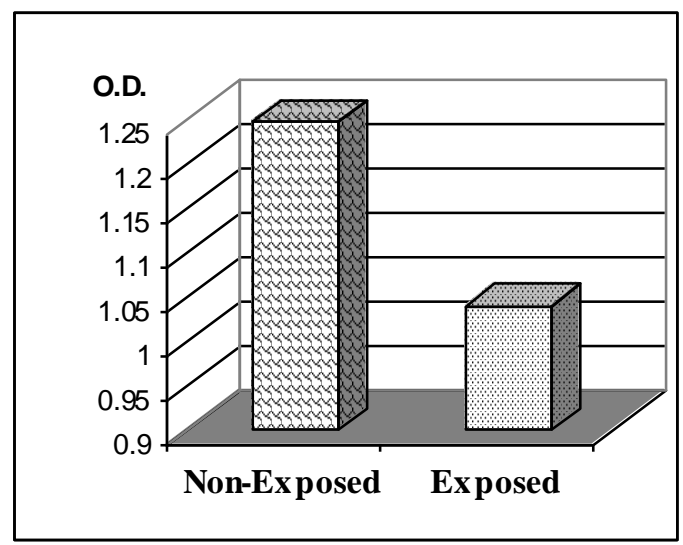

Figure-3 Effect of exposure to ultra violet-B rays on melanin pigments distribution as area percent of mice skin

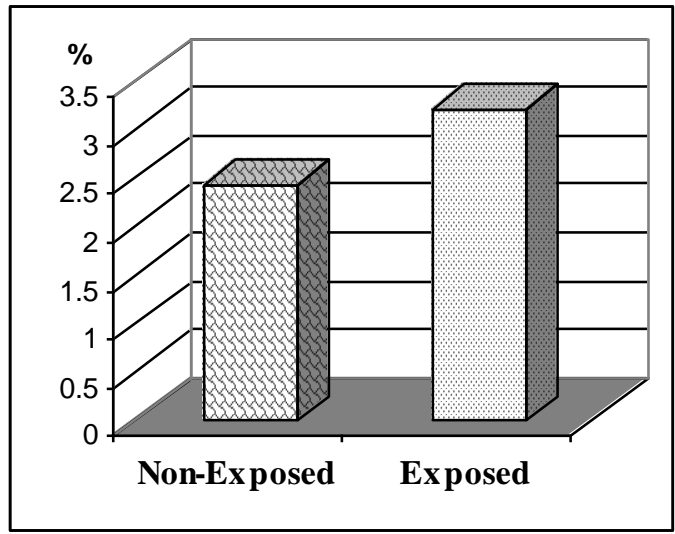




\section{Plate - 1}

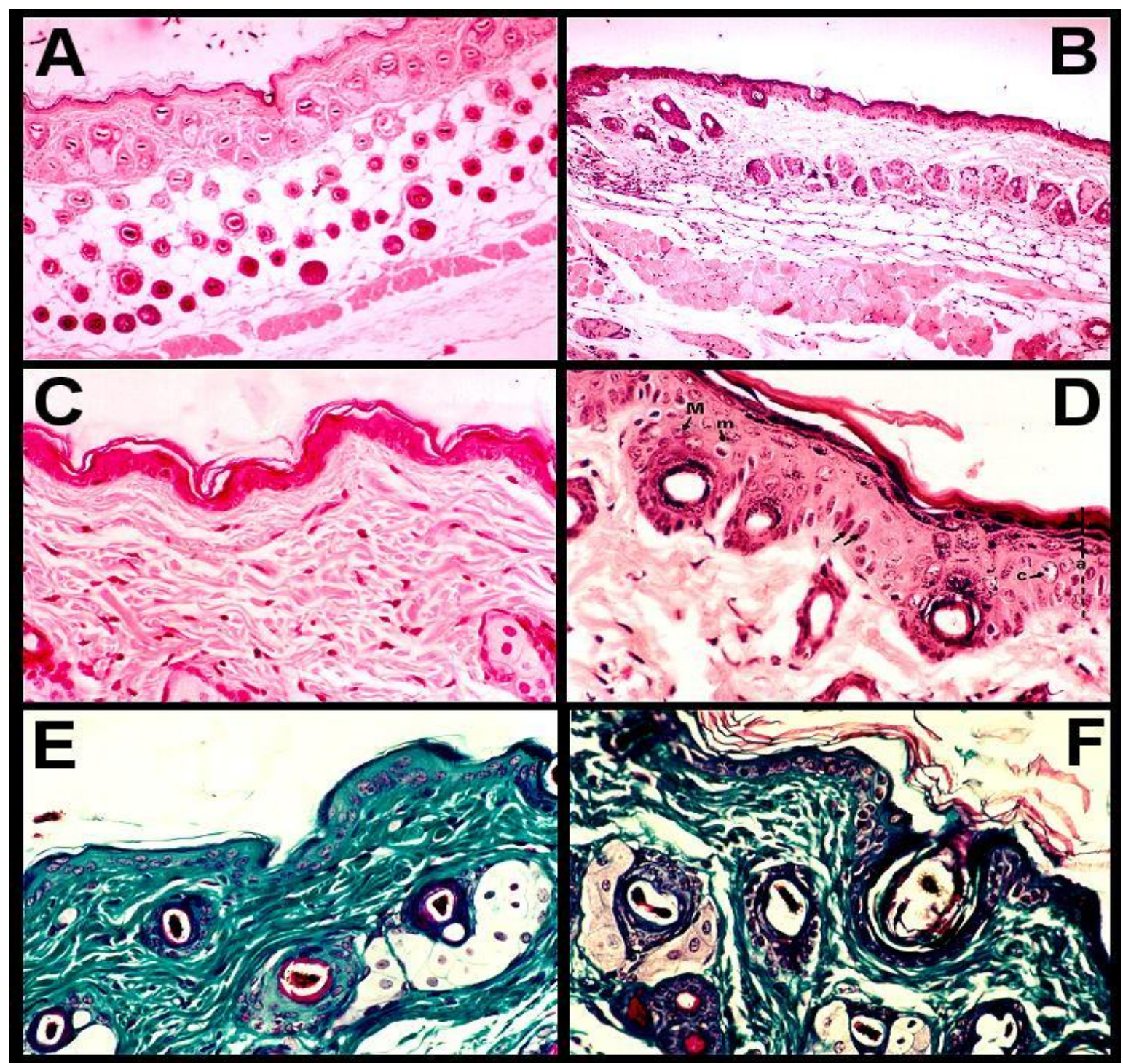

1-A A computerized photomicrograph of longitudinal section in the non-exposed skin of mice, showing the different layers of skin and the underlying dermis containing numerous hair follicles and hypodermis showing Panniculus carnosus. (Hx and E. stain, X100)

1-C A computerized photomicrograph of longitudinal section in the non-exposed skin of mice, showing very thin epidermis, and the underlying dermal collagenous fibers; fine in the dermal papillae and dense irregular in reticular dermis. (Hx and E. stain, X400)

1-E A computerized photomicrograph of longitudinal section in the non-exposed skin of mice, showing the underlying dermal collagenous fibers; in the dermal papillae and reticular dermis. (Masson's Trichrome. stain, X400)

1-B A computerized photomicrograph of longitudinal section in the skin of mice exposed to ultra violet-B rays, showing marked dermal acanthosis. (Hx and E. stain, X100)

1-D A computerized photomicrograph of longitudinal section in the skin of mice exposed to ultra violet-B rays, showing marked dermal acanthosis, keratinocytic atypia, chromatin margination and an increase in mitotic figures. (Hx and E. stain, X400)

1-F A computerized photomicrograph of longitudinal section in the skin of mice exposed to ultra violet-B rays, showing degenerated delicate strands of collagenous fibers in the dermis. (Masson's Trichrome. stain, X400) 


\section{Plate - 2}

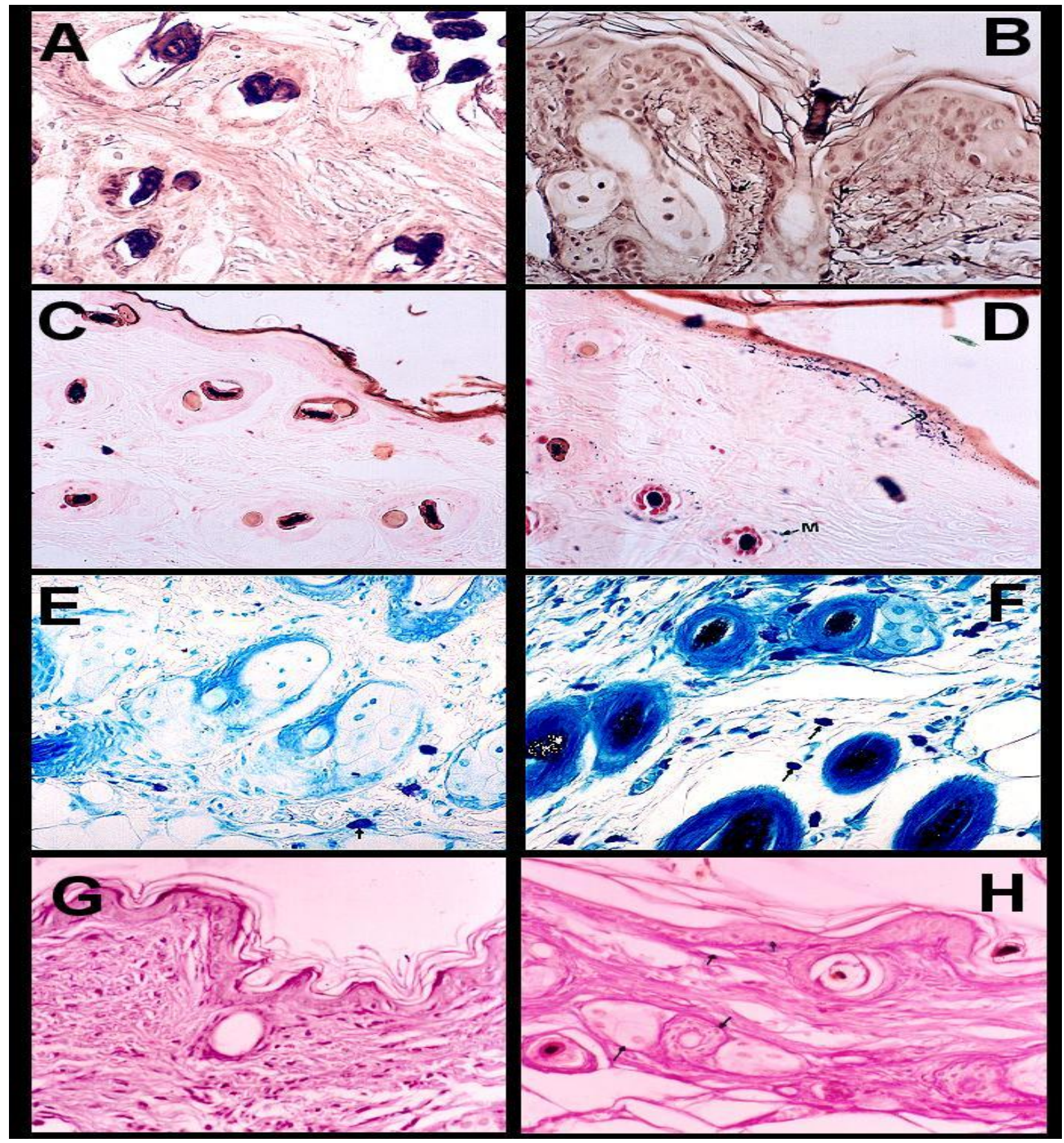

2-A A computerized photomicrograph of longitudinal section in the non-exposed skin of mice, showing thin and sparse elastic fibers arranged in fibrillary pattern in the dermis. (Orcein. stain, X400)

2-C A computerized photomicrograph of longitudinal section in the non-exposed skin of mice, showing melanin pigments in hair follicles and in some areas of epidermis. (Masson Fontana stain, X400)

2-E A computerized photomicrograph of longitudinal section in the non-exposed skin of mice, showing mast cells as ovoid shape purple cells with round blue nucleus around dermal blood vessels. (Thionin stain, X400)

2-G A computerized photomicrograph of longitudinal section in the non-exposed skin of mice, showing PAS positive materials in the basement membrane at dermo-epidermal junction, around blood vessels and sebaceous glands. (PAS technique. stain, X400) 
2-B A computerized photomicrograph of longitudinal section in the skin of mice exposed to ultra violet-B rays, showing marked increase in the thickness of elastic fibers and loss of fibrillary in the dermis. (Orcein. stain, X400)

2-D A computerized photomicrograph of longitudinal section in the skin of mice exposed to ultra violet-B rays, showing an increase in the amount of melanin pigments in hair follicles and in the epidermis. (Masson Fontana stain, $\mathrm{X} 400)$

2-F A computerized photomicrograph of longitudinal section in the skin of mice exposed to ultra violet-B rays, showing marked increase in the number of mast cells around dermal blood vessels. (Thionin stain, X400)

2-H A computerized photomicrograph of longitudinal section in the skin of mice exposed to ultra violet-B rays, showing an increased in the PAS positive materials in the basement membrane at dermo-epidermal junction, around blood vessels and sebaceous glands. (PAS technique. stain, X400)

\section{Discussion}

The skin serves as the major waterproof barrier protects mammals from environmental conditions.

Histologically, skin composed of epidermis, dermis and hypdermis. Five epidermal strata are distinguished by keratinocytes (shape, staining affinity, contents and orientation); basale, spinosum, granulosum, lucidium and corneum. Mitotic figures are common in the stratum basale, due to their role in skin renewal (Gartner and Hiatt, 1997).

Cells of stratum spinousum contain lamellar bodies, which playing roles in the barrier function. Both above strata are responsible for turnover of epidermal keratinocytes (Stevens and Lowe, 1997).

Clinically, the exposure of skin to ultra violet radiation results in many visible clinical signs in the skin appearance. These changes are preceded by alteration of molecular and biochemical changes in the skin structure (Kaminer, 1995).

The early effect of ultra violet-B radiations is on DNA and skin chromophores and leads to inhibition of cellular metabolism and subsequent cellular damage (Harber et al, 1989, Carson and Lois, 1995, and Nishigori et al, 1996).

The current studies showed a statistically significant increase in the epidermal thickness in the area exposed to ultra violet-B radiations.

These finding is agreed with the work of Sheehan and Yaung, 2000. They reported that, the acute exposure of skin to ultra violet-
$B$ radiations caused faulty degradation of stratum corneum desmosomes, which led to epidermal thickening.

Also they stated that, keratinocytic damage was found after $30 \mathrm{~min}$ after exposure, became prominent at $24 \mathrm{hrs}$ and at $72 \mathrm{hrs}$ the damaged keratinocytes constituted a parakeratotic stratum corneum with increased mitotic activity and cellular redistribution of epidermal melanin pigments.

The present study showed an increase in the mast cells population in the dermis of exposed skin.

In 1997, Fitzpatrick reported that, after $24 \mathrm{hrs}$ of exposure to ultra violet radiations, the dermis showed prominent vasodilatation, edema, neurophils, mononuclear cells infiltrations followed by mast cells degranulation in papillary dermis. Also he stated that these findings were clinically accompanied with skin swelling, erythema, pain warmth sensation and tanning.

The present work revealed an increase in the collagen and elastic fibers in area exposed to ultra violet-B radiations, and there was a statistically significant decrease in the optical density of dermal collagen fibers.

Similar findings were observed by Uitto, 1997, Ortonne and Mark, 1999, they found a quantitative and qualitative change in elastic fibers in dermal photodamage. Also they reported that, an increase in collagen and ground substance in photodamaged dermis, and a significant correlation was found between reduced levels of collagen I and the severity of photodamage of human skin. 
In the hairless mouse, the collagen loss is accompanied by compensatory over production of reticulin fibers, which in sunprotected skin are limited to the basement membrane zone and do not extend into the dermis (Gilchrest, 1996).

The current works showed an increase deposition of PAS positive material in the skin exposed to ultra violet-B radiations.

These findings are agreed with the work of Uitto (1997). He stated that, there were biochemical changes in the ground substance of photodamaged dermis, which included an increase in glycosaminoglycans and proteoglycan complex.

The current study concluded the defined pathological changes in the skin exposed to ultra violet-B rays, and adequate protective prophylactic application must be used to minimize the effect of ultraviolet radiations exposures.

\section{References}

1. Carson D. A. and Lois A, (1995): Cancer progression and P53. Lancet, 346: 1009-1011

2. Chen S., Kess I., and Tramposch K. M., (1992): Effect of All-trans-retinoic acid on UVB irradiated and non-irrediated hairless mouse skin. J. Invest. Deramatol. 98: 248-254

3. Fitzpatrick R. E., (1997): Laser resurfacing of Rhytides., Dermatologic. Clinic Vol. 15 Number 3 July: 431-446.

4. Drury R. A. and Wallington J, (1996)" Carleton's histological techniques. $5^{\text {th }}$ ed. Oxford Univ. Press.

5. Gartner I. P. and Hiatt J. L., (1997): Skin in: Color textbook of Histology. W. B. Saunders Company. New York, 14: 269-283
6. Gilchrest B. A., (1996): A review of skin aging and its medical therapy. Br. J. Dermatol, 313: 1621-1622.

7. Griffith C.E.M., (1992): The clinical identification and quantification of photodamage. Br. J. Dermatol. 127(Suppl. 41): $37-42$

8. Harber L. C., Bickers D. R., and Kochevar I., (1989): Photosensitivity disease, Principles of diagnosis and treatment $2^{\text {nd }}$ ed. Blackwell Toronto. 115-117.

9. Kaminar M. S., (1995): Photodamage magnitude of the problem from photodamage. Gilchrest, B. A. (ed) Blackwell Science. Cambridge. 1: 1-11

10. Leyden J. , (2001): What is photoaged skin? European Journal of Dermatology. Vol. 11, Issue 2, March- April 2001: 165-171.

11. Nishigori C., Yarosh D. D., and Eullrich S. E., (1996): Evidence that DNA damage triggers interleukin 10 production in UV murine keratinocytes. Prc. Nat. Acad. Sci. USA. 93: 10354-9

12. Ortonne J. P. and Mark R., (1999): The treatment of skin photoaging. In: Photodamaged skin. (ed.) Martin Dunitz. N.Y (8): 121-142.

13. Sheehan J. M and Yaung R. A. , (2000): Ultraviolet radiation induced apoptosis in human skin invivo radiate. Prot. Dosim. 91(13) : 74-90.

14. Stevens A. and Lowe J. S., (1997): Skin: In Human Histology. $2^{\text {nd }}$ ed. Mosby. New York. 18: 355-369.

15. Uitto J., (1997): Understanding premature skin aging. N. Eng. J. Med. Nov. 13. Vol. 337: 20-39.

16. Welsh B. M., Mason R. S., and Hallida G. M., (1999): Topical all-trans retinoic acid augments ultraviolet radiation increases in activated melanocyte numbers in mice. $J$. Invest. Dermatol. March 112: 3271-3278. 
دراسة مجهرية وهيستوكيميائية كمية علي جلد الجرذان تحت تأثير التعرض للأشعة الفوق بنفسجية (ب) برذب ان

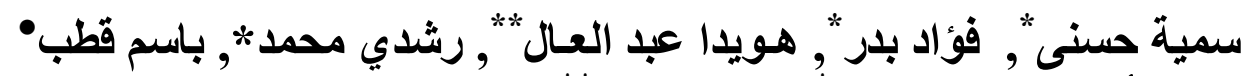

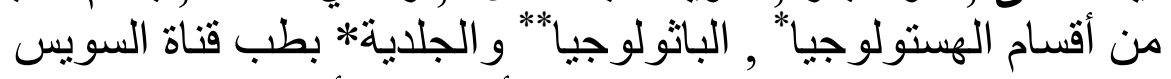

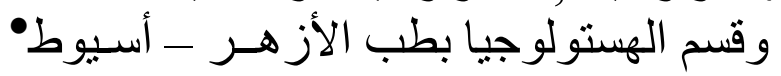

أجريت هذه الدراسة علي عدد 24 من ذكور الجرذان البيضاء البالغة لدراسة تأثئير

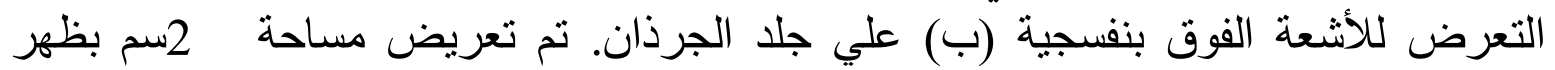

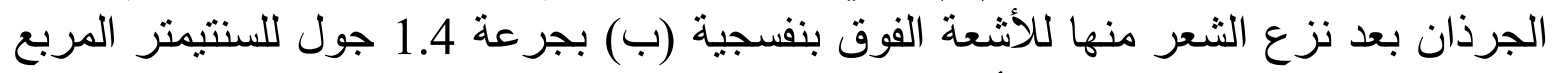

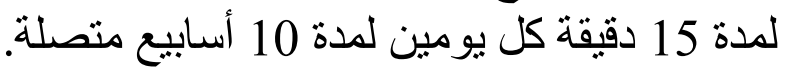

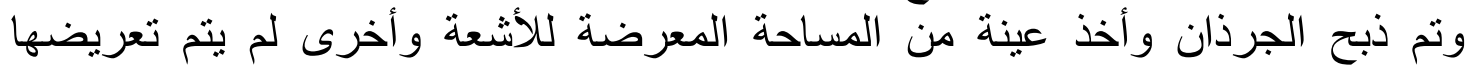

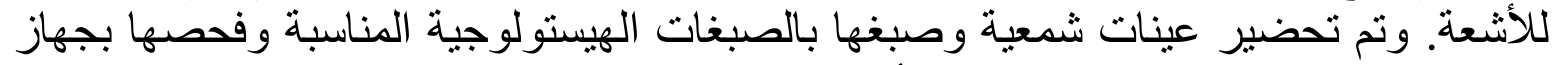
تحليل الصور بالكمبيوتر وتحليل النتائج أحصائيا.

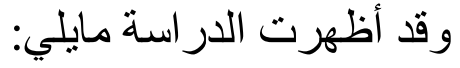

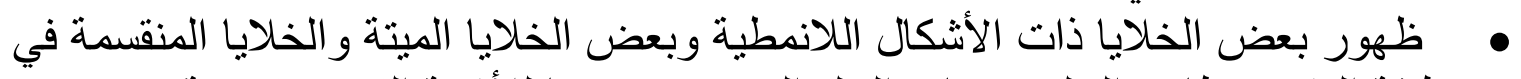

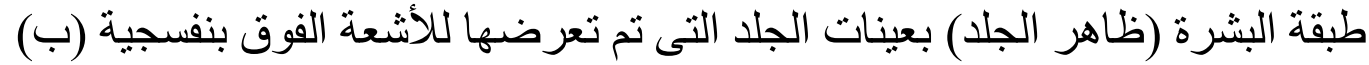

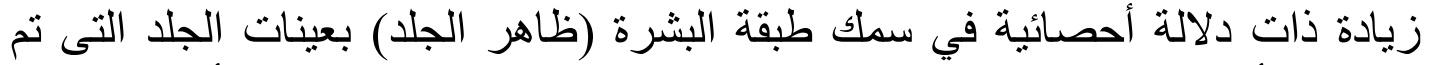

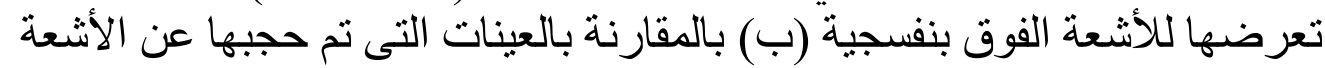

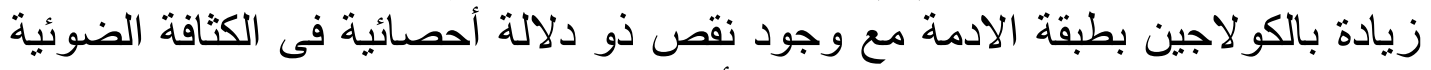

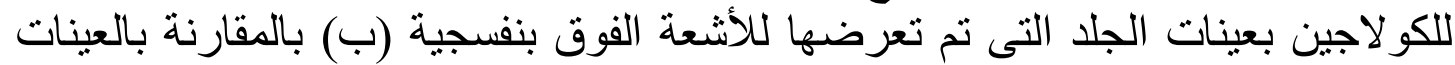

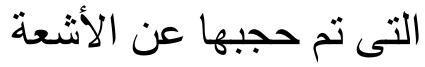

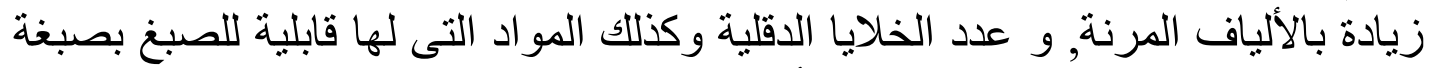

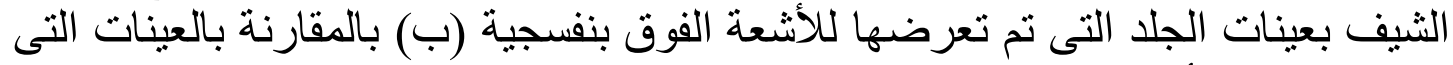

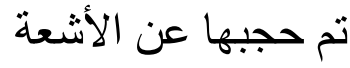

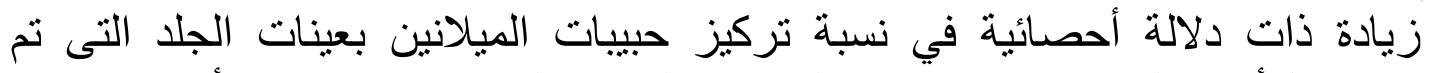

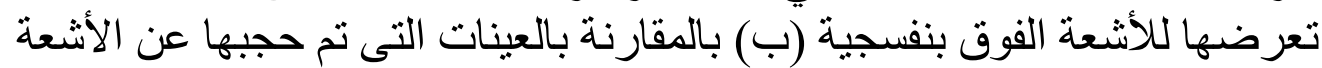

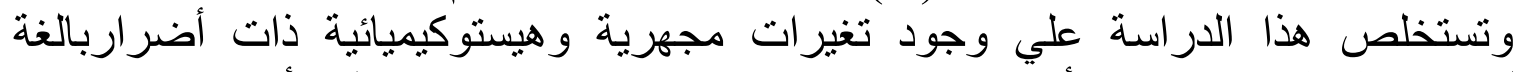

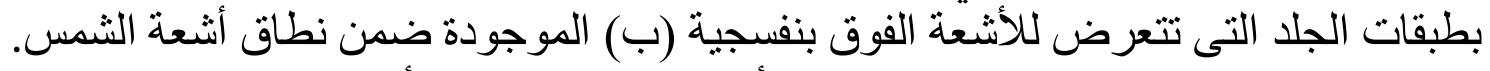

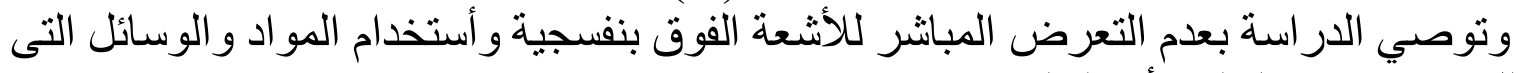

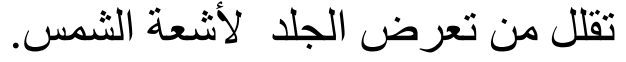

